\title{
Determinants of Climate Change Awareness among Rural Farming Households in South Africa
}

\author{
Oduniyi, Oluwaseun Samuel ${ }^{1}$, Antwi Micheal ${ }^{1}$, Busisiwe Nkonki-Mandleni ${ }^{2}$ \\ ${ }^{1}$ University of South Africa, Florida Campus, South Africa \\ 2Mangosuthu University of Technology, Umlazi, KwaZulu-Natal, South Africa \\ sammiey2007@yahoo.com, antwima@unisa.ac.za, mandleni@mut.ac.za.
}

\begin{abstract}
Climate change and rural livelihood capitals remain the major inextricable dimensions of sustainability in this twenty-first century globally. It is known to be an important challenge facing food security status among African countries. Additionally, it is an indisputable fact that climate change and agriculture are intertwined. In view of this, climate change awareness needs to be strengthened in the rural farming households. The study was carried out in Ngaka Modiri Molema District Municipality, in the North West Province of South Africa to determine awareness of climate change. Stratified random sampling technique was used to select three hundred and forty-six (346) farmers who were interviewed from the study area. Data were analyzed using statistical package for social sciences (SPSS). The binary logistic regression model was employed to analyse the factors driving climate change awareness. The study established that majority of the rural farmers in the study area aware of climate change, in which farm size, education, who owns the farm, information received on climate change, source of climate change information, climate change information through extension services, channel of information received on climate change and support received on climate change are statistically significant $(p<0.05)$ determinants of climate change awareness in the study area.
\end{abstract}

Keywords: Climate change awareness, maize production, and binary logistic regression model.

\section{Introduction}

Climate change and agriculture are two intertwined entities. A change in weather condition over a certain period of time is identified as climate change. The activities of agricultural production impact climate change adversely, vice versa. Climate change has become an imperative challenge facing African countries, while the impact is largely due to little revenue, more dependence on climate-sensitive sectors such as agriculture, and the lack or poor ability to get acclimatized to the changing climate (Belloumi, 2014). According to the United Nation Framework for Climate Change (UNFCCC, 2011), climate change significantly affects rural communities particularly in Africa who rely mainly on farming activities and natural forest resources for their livelihoods. Likewise, there is a collective confirmation that climate change will intensely affect the African continent and will be one of the thought-provoking concerns for future growth, particularly in the arid regions (Huq et al., 2004; Kurukulasuriya and Mendelsohn, 2006). James and Washington (2013) reported that temperatures in all African countries are estimated to rise faster than the global average increase during the 21st century. Subsequently, the African continent is anticipated to be the utmost affected and susceptible to the effects of climate change (Hummel, 2015; Bewket, 2012).

Resilience to climate change among small-scale farmers lies in adaptation strategies and coping mechanisms. However, adaptation to climate change can only be achieved when awareness is prioritised. Awareness to climate change is a form of knowledge or education where an individual is thought to be conscious of the prevailing climatic condition. Rural household farmers need an understanding and awareness of climate change in order to cope effects of climate change. To this effect, the study seeks to analyse the determining factors of climate change awareness among the rural farming households of North West Province in South Africa. The study is expected to foster better information and understanding of climate change, enable the stakeholders and the extension officers to understand what prevents awareness of climate change, and lastly, to improve adaptation strategies among the rural farming households in order to maximize profit, improve rural livelihood especially those who rely on agriculture for survival and enhance food security among rural farming households. Thus, there is a need to research on awareness about climate change in the study area, in other words, for rural household farmers to be aware of climate change, the above variables. 


\section{Literature Review}

Agriculture is highly exposed to climate change, as farming activities directly depend on climatic conditions. It follows that global climate change impact on agricultural production should be considered important (Rosenzweig and Parry, 1994). Numerous global problematic challenges currently experienced in the world today stemmed from global scientific collaborations that rely mainly on the ecosystem. The upshots gave rise to the excessive and formidable environmental problem cited by Udenyi (2010). According to Houghton (2002), the earth's average surface temperature has increased by $10^{\circ} \mathrm{F}$ just over the last century and consequently, climate aggravates a serious negative impact on crop yield, which has occasioned a reduction in the production of food. IPCC (2001) verbalized that climate change is a statically significant difference in weather conditions that hold for a prolonged period of time, usually decades or more. Analogously, IPCC (2007) advanced that it is a change in the state of the climate that can be deciphered via the instrumentation of statistical examination. In consequence, the atmospheric variation is particularly recognizable through the changes in the mean and/or the variability of its properties, and that persevere for an extended period, typically decades or longer.

According to Hassan (2015) climate change refers to any change in climate over time, whether due to natural variability or as a result of human activity. Equivalently, UNFCCC (2009) attested that climate change is a change in the climate system that can be directly or indirectly ascribed to the activities engaged in by human beings, which subsequently eventuate in the alteration of the global atmospheric composition. Also, a change in climate variability such as rainfall, wind, and temperature are depictions of climate change. World Meteorological Organisation (WMO, 2009), vocalized that climate change is a representation of a statistical description of weather of a region, with regards to its mean and variability of the parameters, for example, when the variation of temperature and precipitation span over 30 years. Appositely, Cruz et al. (2007) indicated that climate change pictures changes that are marked by an increase in the occurrence and high events of extreme weather. Climate change can be characterized as an increased effect of global warming. Climate change is expressed as an extreme temperature, uncontrolled rainfall resulting in a flood, rainfall which exhibits notable spatial and temporal variability. In the same vein, Wang et al. (2010) explained that climate change will generate continuing variability regarding the rise in sea level, increased temperatures resulting from movement of climatic zones and changes in precipitation patterns.

The impact of climate change is very likely to affect food production at the global, regional, and local level. In every society, agriculture and food are issues that are very sensitive to climate change variability. Naturally, climate change will have overarching impacts on crop, livestock and fisheries production, and will increase the prevalence of crop pests (Campbell et al., 2016). For instance, Lobell et al. (2011) noted the negative impact of climate change on crop yield. Climate impact studies on crops are predominate, but impacts on fisheries and livestock production are equally preponderant (Creighton et al., 2015; Herrero et al., 2015). In this regard, rural household farmers need to be aware of the climate change impact. In order to understand the dynamics of climate change, there is a need for awareness. Sujit and Padaria (2010) emphasized that there was a mixed result among Indian farmers, in which the majority of the rural farmers lacked detailed information and understanding of climate change. Findings from Thaddeus et al. (2011), reported that the level of awareness about climate change among the local communities in the Niger Delta region of Nigeria was still low.

Majority of the farmers in the region (about 60\%) knew nothing or little on climate change and its impacts. Adetayo (2012) explained that the level of climate change awareness among the poor resource rural farmers was still low. In the same frame of thought, Aphunu et al. (2007) reported that most farmers claimed to be aware of climate change but, the understanding and the level of knowledge on the impact and adaptation were still low. According to Tembo et al. (2017), it was reported that majority of the farmers (77.2\%) were aware of issues related to climate change and its consequences on agricultural production and the environment. Also, Oduniyi (2014) indicated that climate change awareness among the small-scale maize farmers in Mpumalanga Province of South Africa was low. This study seeks to identify factors that determine climate change awareness among the rural household farmers in the North West Province of South Africa. This study was intended to add to existing literature and contribute to the body of knowledge on climate change awareness. 


\section{Methodology}

Study Area: The study was carried out in the Ngaka Modiri Molema (NMM) District Municipality of the North West Province. The province is located in the north of South Africa sharing a border with the Republic of Botswana and the Kalahari Desert to the west, where Gauteng Province is found on the east and the Free State to the south. The district municipality is the capital of the province which is situated at the centre of the province. The district consists of Mahikeng, Ditsobotla, Ramotshere Moiloa, Tswaing, and Ratlou local municipalities. The area of the district is $28,206 \mathrm{~km} 2$ with a population of 842,699 . The main economic activity in the district is agriculture, and the towns include Lichtenburg, Sannieshof, Delareyville, Zeerust, Mahikeng, Coligny, Disaneng, Mmabatho, Biesiesvlei, Groot Marico, Ottosdal, Setlagole, Madibogo, Kraaipan, and Ottoshoop.

Method of Data Collection: The study area is known as one of the largest maize producing areas in South Africa. Farming is the primary occupation for the rural households. The area was selected because of the high concentration of small-scale maize farmers in the area. The data used in the research were primary and secondary data. Data were collected using a validated, pre-tested structured questionnaire, which consisted of coherent questions related to household socio-economic characteristics (demography), climate change and its awareness. The questionnaires were explained to the local extension officers before the survey was undertaken because they understood the farmers better and could translate the questionnaires into the local language. This was followed by face to face interviews and focus group discussion in each local municipality where each session lasted for about 45 minutes.

Population, Sampling Procedure, and Sample Size: A total number of 346 questionnaires were administered to the farmers in the district using the stratified random sampling technique. The sampling was carried out by grouping the population of the small-scale maize farmers from the five local municipalities in the district into strata. Thereafter, a random sampling technique was used to select a specific number of individual farmers from each stratum. Thus, there is a need to determine the factors responsible for climate change awareness among rural farming households. The outcomes of this study are expected to help to develop policy measures and framework to improve rural awareness. The findings obtained, and the recommendation can also be used by the policymakers and the stakeholders in dealing with factors contending against climate change awareness.

Statistical Analysis: The collected data were coded, cleaned, captured, and analyzed using the statistical package for social sciences (SPSS). Multicollinearity analysis was employed to remove variables that were correlated to each other from the list of variables obtained from the questionnaires after which binary logistic regression model (BLRM) was used to determine if a rural household farmer is aware of climate change or not. Logistic regression is a multivariate technique used to study the relationship between a dichotomous dependent variable and one or more independent variables (Molla-Bauza et al., 2005). A dichotomous variable is a variable that takes only two values, 1 and 0 correspondingly. Assuming $\mathrm{Y}$ is a binary response (dependent) variable, and $\mathrm{X},\left(X_{1}, X_{2} \ldots . . . X_{k}\right)$ are a set of independent or explanatory variables which could be discrete, continuous, or a combination.

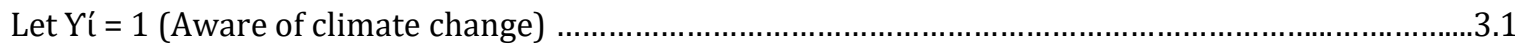

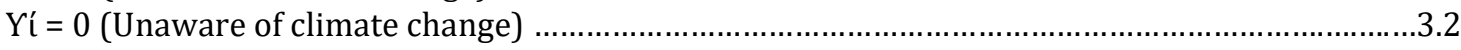

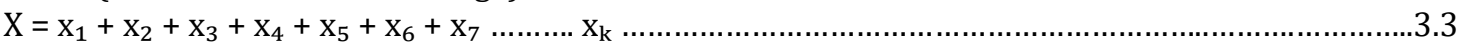

Where $X$ could be signified as of household gender $\left(x_{1}\right)$, household age $\left(x_{2}\right)$, farming as a major income $\left(x_{3}\right)$, type of farm $\left(\mathrm{x}_{4}\right)$..................................

Assuming that climate change awareness is a function of household gender $\left(\mathrm{x}_{1}\right)$, household age $\left(\mathrm{x}_{2}\right)$, farming

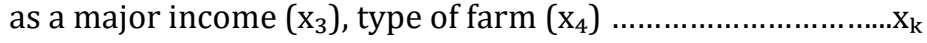

The initial model will be given as:

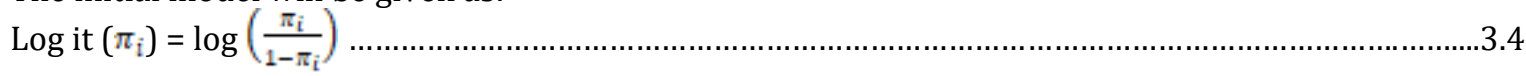

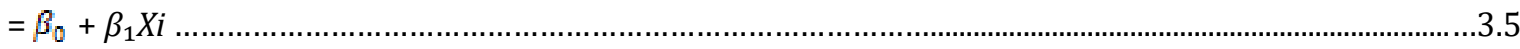

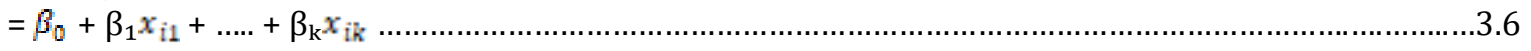

Then the logistic regression model can be expressed as: 


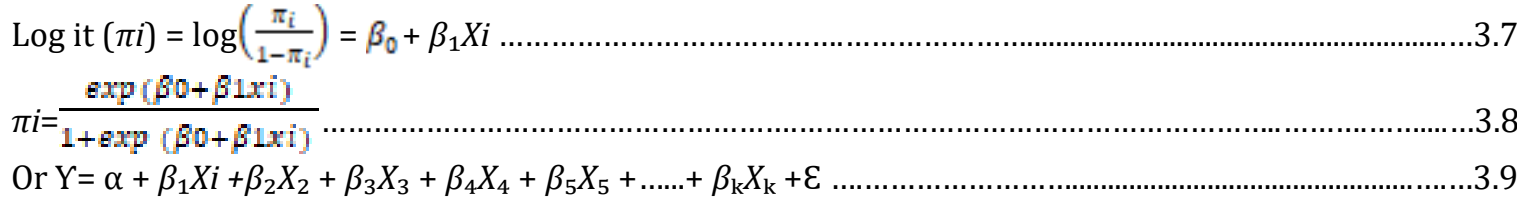

Where:

The variable $\varepsilon$ is called the error term or disturbance. It is termed "noise" reflecting other factors that influence climate change awareness. It captures the factors other than $\mathrm{x}$ affecting $\mathrm{y}$.

$Y=$ dependent variable

$\mathrm{x}_{1}=$ independent variables

$\beta_{1}=$ regression coefficients

The model for logistic regression analysis assumes that the outcome variable, Y, is categorical (e.g., dichotomous), taking on values of 1 (i.e., yes) and 0 (i.e., no). Hypothetically, population proportion of cases for which $Y=1$ is defined as $p=P(Y=1)$. Then, the proportion of cases for which $Y=0$ is $1-p=P(Y=0)$. In the absence of other information, we can estimate $\mathrm{p}$ by the sample proportion of cases for which $\mathrm{Y}=1$. However, in the regression context, it is assumed that there is a set of predictor variables, $\mathrm{x}_{1} \ldots \ldots \ldots . . . \mathrm{x}_{\mathrm{k}}$, that are related to $\mathrm{Y}$ and, therefore, provide additional information for predicting $\mathrm{Y}$.

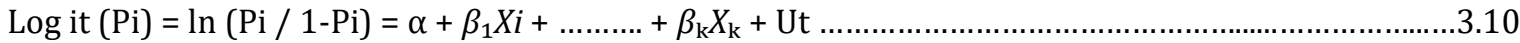

Where:

$\ln (\mathrm{Pi} / 1-\mathrm{Pi})=\log$ it for farmers awareness choices (Yes or No)

$\mathrm{Pi}=$ Aware of climate change;

1 - $\mathrm{Pi}=$ Unaware of climate change;

$\beta=$ coefficient

$\mathrm{x}_{1}=$ covariates

$\mathrm{Ut}=$ error term

When the variables are fitted into the model, the model is presented as:

$\ln (\mathrm{Pi} / 1-\mathrm{Pi})=\alpha+\beta_{1} X i+\beta_{2} X_{2}+\beta_{3} X_{3}+\beta_{4} X_{4}+\beta_{5} X_{5}+\ldots \ldots+\beta_{\mathrm{k}} X_{\mathrm{k}} \ldots \ldots+\mathrm{Ut}$.

\section{Results and Discussion}

This section presents the determinants of climate change awareness among the farming households in the study area. To achieve this, a binary logistic regression model was employed. Firstly, Pearson correlation analysis was carried out to determine the strength of association between variables, either positive or negative, as well as the relationship between the dependent variable and the independent variables. The independent variables employed included the socio-economic characteristics and climate-related information. However, out of all the independent variables, the following variables: farm size, level of education, land acquisition, support received on climate change were negatively associated with the dependent variable. On the other hand, variables such as marital status, who manages the farm, who owns the farm, information received on climate change, the source of information on climate change, extension services, were positively associated with the dependent variable. The dependent variable (climate change awareness categorized in its binary form) was regressed against the explanatory variables mentioned above. Test for multicollinearity among the variables was carried out, showing the variance inflation factor (VIF) for each variable, the mean VIF was 1.455 (See Table 1).

There occurred a high level of tolerance among the variables, which indicated that there was no serious multicollinearity among the variables used in the analysis. The value for Cox \& Snell Square and Nagelkerke R Square were not statistically significant. This concludes that the data fit the model well. As shown in the results, out of the independent variables considered in the model (See Table 2), seven variables were statistically significant, and they determined the awareness of climate change among the respondents in the study area. The variables included farm size, education, who owns the farm, information received on climate change, source of climate change information, climate change information through extension services and the channel of information received on climate change. Farm size was strongly associated with climate change awareness. The variable farm size was statistically significant $(\mathrm{p}<0.05)$ with a negative coefficient $(-2.354)$. This implied that the probability of the household farm size decreased as awareness was made on climate change in the study area with the odd ratio of 0.095 . 
Farming households would tend to operate on a small scale as climate change awareness increased. This reason is not far-fetched from the fact that, most small-scale household farmers in the study area were poor and less resourced, and coping with climate change was a challenge, even if they were aware. Farmers with large farm size mostly had resources and they were likely to have more capacity to try out and invest in climate risk coping strategies (Ali and Erenstein, 2017). Thus, farmers in the study area opted to reduce the amount of land cultivated as an adaptation measure (see Table 2) to climate change in other to maximize productivity. Climate change awareness and level of education were expected to enhance informed decisionmaking and a significant role in increasing the adaptation and mitigation capacities of household farming. In this study education was statistically significant $(\mathrm{p}<0.05)$ with a negative coefficient $(-1.326)$, that is, education decreased the probability of climate change awareness with an odds ratio of 0.265 . This finding implied that education had a negative influence on the farmers' awareness of climate change. This result was supported by Bayard et al. (2007), who reported similar results that education significantly, but negatively, affected climate change awareness.

Mandleni (2011) aligns with the findings of this current research because the researcher also submitted that education significantly but negatively affected awareness about climate change. On the contrary, the studies carried out by Deressa et al. (2009), Deressa et al. (2010) and Maddison (2006), recorded that education of household heads increased the probability of awareness on climate change. The variable (who owns the farm) was found to be statistically significant $(\mathrm{p}<0.05)$ to climate change awareness with a positive coefficient (2.899). Who owns the farm increased the probability of awareness to climate change? Majority of the households farming who owned the farm were individual households. This indicates that individual household who owns a farm tend to be more aware of climate change in order to cope and engage in adaptation measures to improve food production and sustain a livelihood. This is in consonance with Shultz et al. (1997) study, for the examination indicated that land ownership individually managed, is widely believed to encourage the awareness. Climate change awareness and the information received are positively associated. Receiving information on climate change increased the probability or likelihood of climate change awareness. The result revealed that information received on climate was statistically significant $(p<0.05)$ to climate change.

Most of the farming households in the study area indicated that they had access to radios, flyers, magazine the local newspaper, amongst many others, which provided information on climate change awareness. Evenly, Deressa et al. (2009) reported that information on temperature and rainfall had a significant and positive impact on climate change awareness. Additionally, research on climate change by Bryan et al. (2009) enunciated that information on climate change was found to facilitate climate change awareness and adaptation among the poorest farmers. The source of climate change information was statistically significant $(p<0.05)$ but negatively affected climate change awareness in the study area. Majority of the respondents obtained climate change information from the media such as radio as they did not have access to the internet, an indication that information technology remained a challenge. This finding implied that sources of information were not increasing climate change awareness. The findings harmonized with Maponya and Mpandeli (2012), and Oduniyi (2014), who also found that most farmers in rural areas did not have access to other sources of information such as internet, magazines. Relatedly, Nwagbara and Nwagbara (2017) enounced that in a research conducted in Abia State, Nigeria, the role of radio stations in building awareness of climate change among crop farmers was vital.

The results of the analysis further showed that extension service was statistically significant $(\mathrm{p}<0.05)$, with a positive association, and it increased the likelihood or probability of climate change awareness. Extension services provided a vital source of information on climate change as well as agricultural production and management practices. This is not surprising because the investigation evinced that the majority of the farming household was already aware of climate change. Various studies in developing countries, including Ethiopia, reported a strong positive relationship between access to information and the adoption behavior of farmers (Yirga, 2007). The innovation and information obtained by the farmers on production activities are determined by the extension agents; thus, extension contacts are the carrier of change (Idris et al., 2012). IFPRI (2007) also attested to the notion that improving access to extension services for farmers has the potential to significantly increase farmers' awareness of changing climatic conditions. 
The channel of information received on climate change by the farming households was statistically significant $(\mathrm{p}<0.05)$, although negatively associated with climate change awareness. This variable decreased the likelihood or the probability of climate change awareness with an odd ratio of 0.167 . The channel of information determines climate change awareness and information dissemination, thus, improving adaptation and reducing the risk of climate change while concurrently sustaining households' livelihood. This is supported by Evelyne and Franzel (2015), who divulged that the channel of information plays a complementary role to facilitate the spread of agricultural technologies and improving farmers' capacities. Information channel is more effective and offers a wide-reaching alternative in supporting agricultural innovation (Ssemakula and Mutimba, 2011; Wellard et al., 2013).

Table 1: Multi Co Linearity Test of Variables

\begin{tabular}{lll}
\hline \multicolumn{2}{l}{ Variables } & \multicolumn{2}{l}{ Colinearity Statistics } \\
& Tolerance & VIF \\
\hline Number of years in farming & 0.576 & 1.736 \\
Farm size & 0.725 & 1.379 \\
Household size & 0.762 & 1.313 \\
Household gender & 0.818 & 1.223 \\
Household marital status & 0.729 & 1.372 \\
Education level & 0.607 & 1.649 \\
Farming as major source of income & 0.566 & 1.768 \\
Types of farm & 0.789 & 1.268 \\
Who manages the farm? & 0.918 & 1.089 \\
Who owns the farm? & 0.791 & 1.265 \\
Land acquisition & 0.746 & 1.341 \\
Information received on climate change & 0.567 & 1.763 \\
Source of climate change information & 0.547 & 1.829 \\
Climate change information through extension services & 0.737 & 1.357 \\
Channel of information received on climate change & 0.745 & 1.342 \\
Support received on climate change & 0.631 & 1.586 \\
Mean VIF & & 1.455 \\
\hline
\end{tabular}

Source: Author's computation (2017)

Table 2: Parameter Estimates of the Binary Logistics Regression Model on Climate Change Awareness

\begin{tabular}{|c|c|c|c|c|c|c|c|}
\hline \multicolumn{2}{|c|}{ Variables } & \multirow{2}{*}{$\begin{array}{l}\text { B } \\
0.513\end{array}$} & \multirow{2}{*}{$\begin{array}{l}\text { S.E. } \\
0.272\end{array}$} & \multirow{2}{*}{$\frac{\text { Wald }}{3.558}$} & \multirow{2}{*}{$\begin{array}{l}\text { DF } \\
1\end{array}$} & \multirow{2}{*}{$\begin{array}{l}\text { Sig. } \\
0.059\end{array}$} & \multirow{2}{*}{$\begin{array}{l}\operatorname{Exp}(B) \\
1.670\end{array}$} \\
\hline & Years of farming & & & & & & \\
\hline & Farm size & -2.354 & 0.805 & 8.550 & 1 & 0.003 & 0.095 \\
\hline & Household size & -0.112 & 0.526 & .046 & 1 & 0.831 & 0.894 \\
\hline & Household gender & -2.258 & 1.504 & 2.254 & 1 & 0.133 & 0.105 \\
\hline & Marital status & 1.150 & 0.620 & 3.443 & 1 & 0.064 & 3.159 \\
\hline \multirow[t]{6}{*}{ 0Step $1^{\mathrm{a}}$} & Education & -1.326 & 0.507 & 6.840 & 1 & 0.009 & 0.265 \\
\hline & Source of income & 0.923 & 1.428 & 0.417 & 1 & 0.518 & 2.516 \\
\hline & Type of farm & 0.042 & 0.363 & 0.013 & 1 & 0.909 & 1.043 \\
\hline & Who manages the farm? & -0.173 & 1.163 & 0.022 & 1 & 0.882 & 0.841 \\
\hline & Who owns the farm? & 2.899 & 1.030 & 7.917 & 1 & 0.005 & 18.164 \\
\hline & Land acquisition & -0.226 & 0.247 & 0.839 & 1 & 0.360 & 0.797 \\
\hline
\end{tabular}




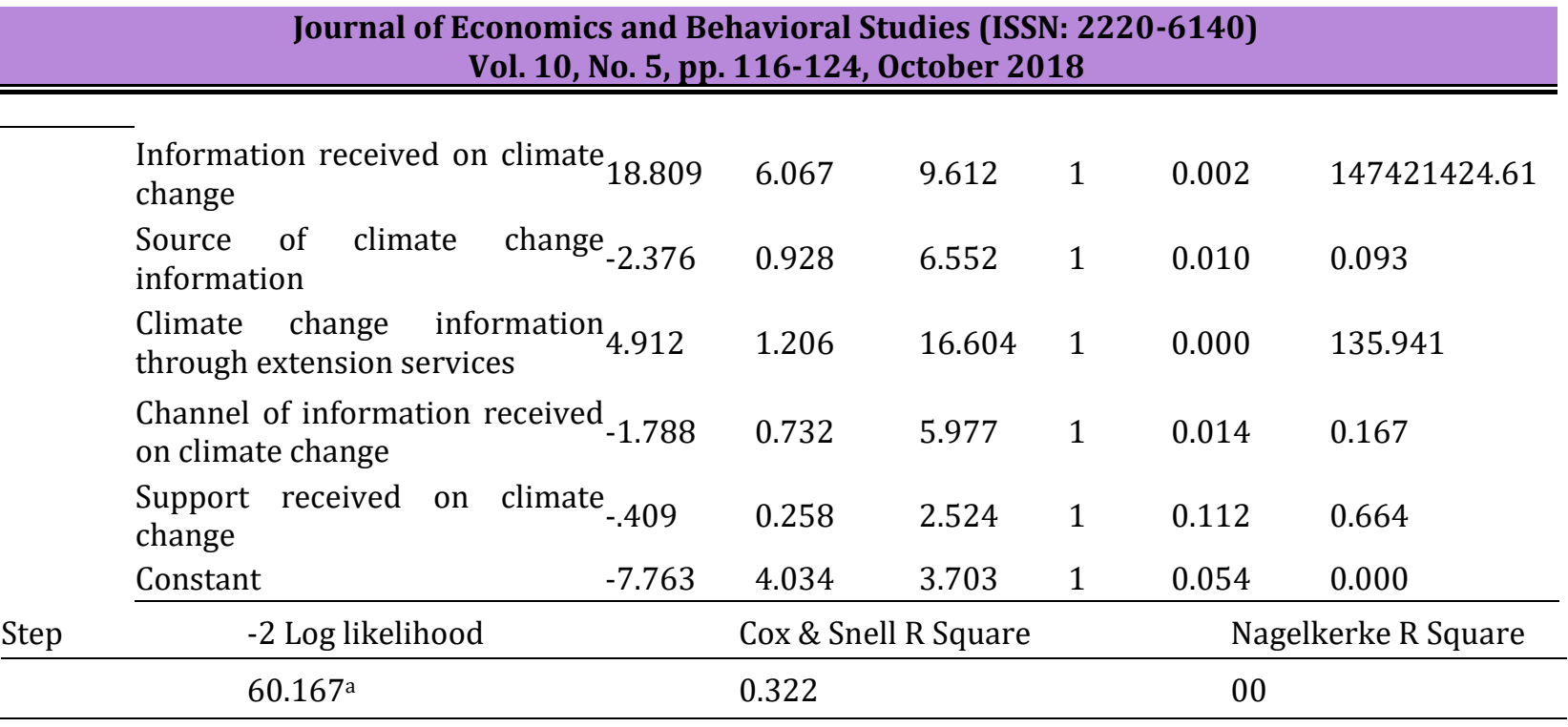

Source: Author's computation (2017)

Note: $\mathrm{p}<0.05 ; \mathrm{p}<0.01$ at $5 \%$ and $1 \%$ level of significant respectively. 0

\section{Conclusion and Recommendation}

The findings in this study revealed that majority of the respondents in the study area were aware but did not fully understand the concept of climate change. The research showed that out of the independent variables considered in the model (See Table 2), seven variables were statistically significant $(\mathrm{p}<0.05)$, and consequently determined the awareness of climate change among the respondents in the study area. The determinant factors to climate change awareness were: farm size, level of education, who owns the farm, information received on climate change, source of climate change information, climate change information through extension services and channel of information received on climate change. It is therefore recommended that the above-mentioned climate change awareness determinants should be considered in any local policy aimed at improving climate change awareness among the farmers in the study area.

\section{References}

Adetayo, A. \& Owolade, E. (2012). Climate change and mitigation awareness in small farmers of Oyo State in Nigeria. Open Science Repository Agriculture, Online (open access).

Ali, A. \& Olaf, E. (2017). Assessing farmers' use of climate change adaptation practices and impacts on food security and poverty in Pakistan. Climate Risk Management, 16, 183-194.

Aphunu G. O. \& Nwabeze. X. (2007). Fish Farmers' Perception of Climate change impact on fish production in Delta State, Nigeria.

Bayard, B., Jolly, C. M. \& Shannon, D. A. (2007). The economics of adoption and management of alley cropping in Haiti, Journal of environmental management, 84, $62-70$.

Belloumi, M. (2014). Investigating the Impact of Climate Change on Agricultural Production in Eastern and Southern African Countries. AGRODEP Working Paper 0003. Washington, DC: International Food Policy.

Bewket, W. (2012). Climate change perceptions and adaptive responses of smallholder farmers in Central Highlands of Ethiopia, Int. J. Environ. Stud, 69(3), 507-523.

Campbell, B. M., Vermeulen, S. J., Aggarwal, P. K., Corner-Dolloff, C., Evan, G., Loboguerrero, A. M., RamirezVillegas, J., Rosenstock, T., Sebastian, L., Thornton, P. K. \& Wollenberg, E. (2016). Reducing risks to food security from climate change. Global Food Security, 11, $34-43$.

Creighton, C., Hobday, A. J., Lockwood, M. \& Pecl, G. T. (2015). Adapting Management of Marine Environments to a Changing Climate: A Checklist to Guide Reform and Assess Progress. Ecosystems, 1-33.

Cruz, R. V., Harasawa, H., Lal, M., Wu, S., Anokhin, Y., Punsalmaa, B., Honda, Y., Jafari, M., Li, C. \& Huu, N. N. (2007). Climate Change: Impacts, Adaptation and Vulnerability. The contribution of Working Group II to the Fourth Assessment Report of the Intergovernmental Panel on Climate Change, Asia. 
Deressa, T., Hassan, R. M., Alemu, T., Yesuf, M. \& Ringler, C. (2008). Analyzing the determinants of farmers' choice of adaptation methods and perceptions of climate change in the Nile Basin of Ethiopia. IFPRI discussion paper 00798, September 2008.

Deressa, T. T., Hassan, R. M., Ringler, C., Alemu, T. \& Yesuf, M. (2009). Determinants of farmer's choice of adaptation methods to climate change in the Nile Basin of Ethiopia. Global Environmental Change, 19, 248-255.

Deressa, T. T., Hassan, R. M. \& Ringler, C. (2010). Perception and adaptation to climate change by farmers in the Nile Basin of Ethiopia. Journal of Agricultural Science, 1-9.

Evelyne, K. \& Franzel, S. (2015). Farmer-to-farmer extension: opportunities for enhancing the performance of volunteer farmer trainers in Kenya.

Hasan, M. (2015). Impacts of Climate Change Will Make You More Worried. Impacts of Climate Change in Bangladesh.

Herrero, M., Wirsenius, S., Henderson, B., Rigolot, C., Thornton, P. K., Havlik, P., deBoer, I. \& Gerber, P. (2015). Livestock and the environment: what have we learned in the past decade? Annu. Rev. Environ. Resour, $40,177-202$.

Houghton, D. (2002). Introduction to climate change: Lecture notes for meteorologists, 13-15.

Hummel, D. (2015). Climate Change, Land Degradation and Migration in Mali and Senegal - some Policy Implications, Migration and Development. Institute of Social-Ecological Research, Hamburger Allee 45, 60486 Frankfurt/Main, German.

Huq, S., Reid, H., Konate, M., Rahman, A., Sokona, Y. \& Crick, F. (2004). Mainstreaming adaptation to climate change in LDCs. Clim Policy, 4(1), 25-43.

Idrisa, Y. L., Ogunbameru, B. O., Ibrahim, A. A. \& Bawa, D. B. (2012). Analysis of awareness and adaptation to Climate Change among Farmers in the Sahel Savannah agro-ecological Zone of Borno State, Nigeria. British Journal of Environment \& Climate Change, 2(2), 216-226.

IFPRI. (2007). Micro-Level Analysis of Farmers' Adaptation to Climate Change in Southern Africa. Centre for Environmental Economics and Policy in Africa (CEEPA) and Environment and production Technology Division. IFPRI Discussion Paper 00714, 25.

IPCC (Inter governmental Panel for Climate Change). (2001). Impacts, Adaptation and Vulnerability. IPCC working group II, Third assessment report. [McCarthy, J.J., Canziani, O.F., Leary, N.A., Dokken, D.J. and White K.S. (Eds.)]. Cambridge University Press.

IPCC. (2007). Climate Change 2007: Impacts, Adaptation and Vulnerability. In: Parry ML, Canziani OF, Palutikof JP, van der Linder PJ, Hanson CE (eds.), Contribution of Working Group II to the IPCC fourth assessment report. Cambridge University Press, Cambridge.

James, R. \& Washington, R. (2013). Changes in African temperature and precipitation associated with degrees of global warming. Clim. Change, 117(4), 859-872.

Kurukulasuriya, P. \& Mendelsohn, R. (2006). Crop selection: adaptation to climate change in Africa. CEEPA Discussion Paper No. 26, Centre for Environmental Economics and Policy in Africa, University of Pretoria, Pretoria.

Lobell, D. B., Schlenker, W. \& Costa-Roberts, J. (2011). Climate trends and global crop production since 1980. Science, 333(6042), 616-620.

Maddison, D. (2006). The perception and adaptation to climate change in Africa. CEEPA Discussion Paper No.10. Centre for Environmental Economics and Policy in Africa, University of Pretoria.

Mandleni, B. (2011). Impact of climate change and adaptation on cattle and sheep farming in the Eastern Cape Province of South Africa. PhD thesis, University of South Africa, South Africa.

Molla-Bauza, M. B., Martinez-Carrasco, M. L, Poveda, A. M. \& Perez, M. R. (2005). Determination of the surplus that consumers are willing to pay for an organic wine. Spanish Journal of Agricultural Research, 3(1), 43-51.

Maponya, P. \& Mpandeli, S. (2012). Climate Change and Agricultural Production in South Africa: Impacts and Adaptation options.

Nwagbara, M. 0. (2017). The Role of Radio Stations in Creating Awareness of Climate Change among Crop Farmers in Abia State. The International Journal of Social Sciences and Humanities Invention, 4, 4. Transactions of the Institute of Geographers, 16, 397 - 399.

Oduniyi, O. S (2014). Climate change awareness: a case study of small-scale maize farmers in Mpumalanga Province, South Africa. A dissertation submitted at the Department of Agriculture and Animal health, The University of South Africa. 
Rosenzweig, C. \& Parry, M. L. (1994). The potential impact of climate change on world food supply, 133-138.

Shultz, S., Fautino, H. \& Melgar, D. (1997). Agroforestry and Soil Conservation; Adoption and Profitability in El Salvador. Agro-Forestry Today, 9, 16-17.

Smit, B. \& Wandel, J. (2006). Adaptation, adaptive capacity and vulnerability. Global Environmental Change, 16(3), 282-292.

Ssemakula, E. \& Mutimba, J. K. (2011). Effectiveness of the Farmer-to-farmer Extension Model in Increasing Technology uptake in Masaka and Tororo Districts of Uganda. African Journal of Agricultural Extension, 39(2), 30-46.

Sujit Sarkar. \& Padaria, R. N. (2010). Farmers' Awareness and Risk Perception about Climate Change in Coastal the ecosystem of West Bengal. Indian Res. J. Ext. Edu, 10(2).

Tembo, M. C., Kuntashula, E. \& Kalinda, Thomson. (2017). Climate Change Awareness and Joint Decision to Adopt Agro forestry and Conservation Agriculture Practices in Zambia.

Thaddeus C. N., Nnaemeka A. C., Chukwudumebi L. E. \& Victoria C. A. (2011). Farmers' perception of Climate Change Governance and Adaptation Constraints in Niger Delta Region of Nigeria.

Udenyi, O. G. (2010). Impacts of Climate Change. Nigeria Social Network.

UNFCCC (United Nations Framework Convention on Climate Change). (2009).

UNFCCC, (2011). Application of methods and tools for assessing impacts and vulnerability and developing adaptation responses. UNFCCC, Bonn, German.

Wang, J., Huang, J. \& Rozelle, S. (2010). Climate Change and China's Agricultural Sector: An Overview of Impacts, Adaptation and Mitigation, ICTSD-IPC Platform on Climate Change, Agriculture and Trade, Issue Brief No.5, International Centre for Trade and Sustainable Development, Geneva, Switzerland and International Food \& Agricultural Trade Policy Council, Washington DC, USA

Wellard, K., Rafanomezana, J., Nyirenda, M., Okotel, M. \& Subbey, V. (2013). A Review of Community Extension Approaches to Innovation for Improved Livelihoods in Ghana, Uganda and Malawi. The Journal of Agricultural Education and Extension, 19(1), 21-35.

WMO (World Meteorological Organization). (2009). Climate Observations and Climate Data Management Guidelines. WCDMP No. 68 - WMO/TD-No. 1481.

Yirga, C. T. (2007). The dynamics of soil degradation and incentives for optimal management in Central Highlands of Ethiopia. Ph.D. Thesis. Department of Agricultural Economics, Extension, and Rural Development, University of Pretoria, South Africa. 